$4910405(2)$

PREPARED FOR THE U.S. DEPARTMENT OF ENERGY, UNDER CONTRACT DE-AC02-76-CHO-3073

PPPL-3017

PPPL-3017

: UC-420,427

\author{
NONLINEAR HYBRID SIMULLATION \\ OF TOROIDICITY-INDUCED ALFVÉN EIGENMODE
}

BY

G.Y. FU AND W. PARK

NOVEMBER 1994
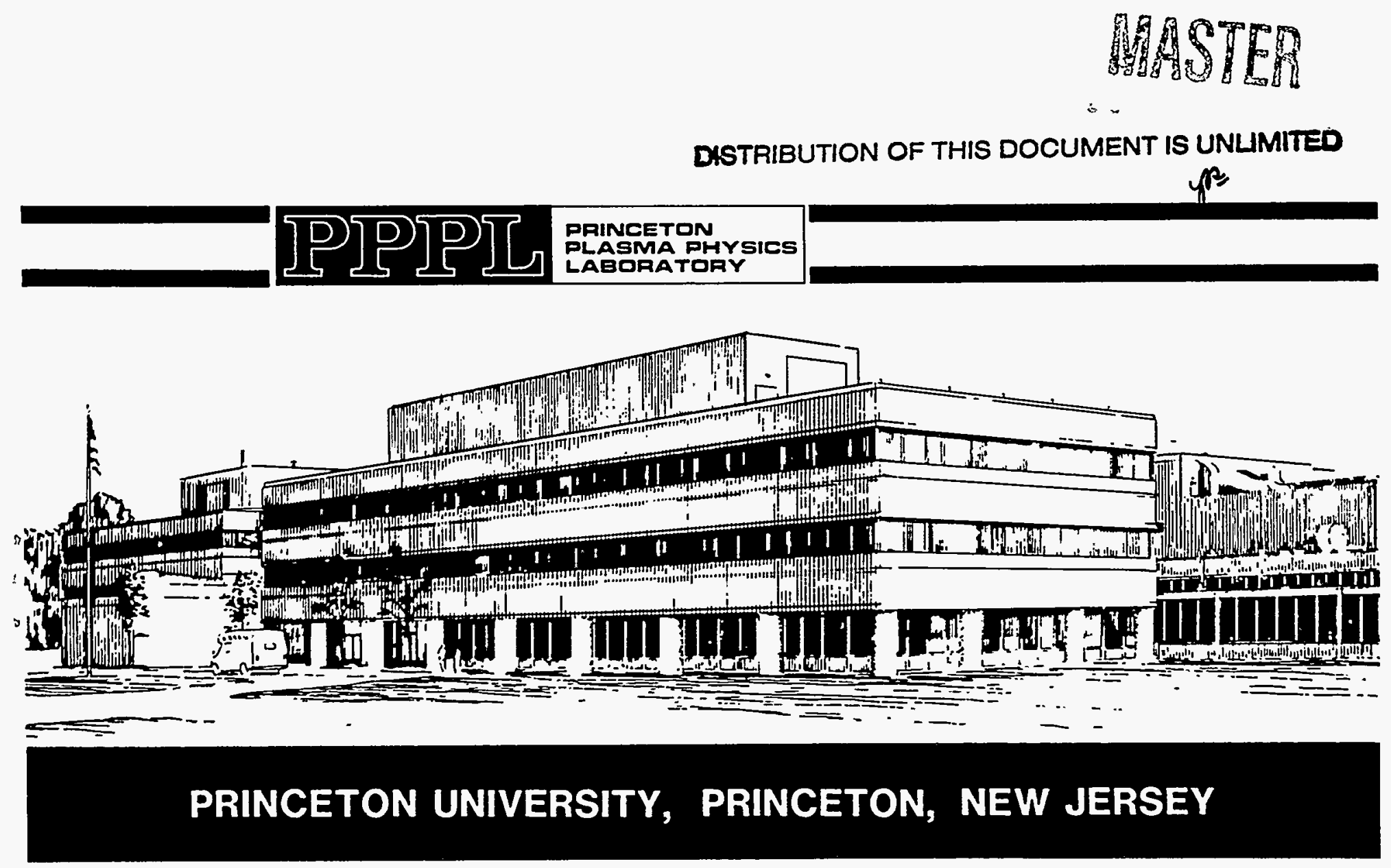


\section{NOTICE}

This report was prepared as an account of work sponsored by an agency of the United States Government. Neither the United States Government nor any agency thereof, nor any of their employees, makes any warranty, express or implied, or assumes any legal liability or responsibility for the accuracy, completeness, or usefulness of any information, apparatus, product, or process disclosed, or represents that its use would not infringe privately owned rights. Reference herein to any specific commercial produce, process, or service by trade name, trademark, manufacturer, or otherwise, does not necessarily constitute or imply its endorsement, recommendation, or favoring by the United States Government or any agency thereof. The views and opinions of authors expressed herein do not necessarily state or reflect those of the United States Government or any agency thereof.

\section{NOTICE}

This report has been reproduced from the best available copy.

Available in paper copy and microfiche.

Number of pages in this report: 14

DOE and DOE contractors can obtain copies of this report from:

Office of Scientific and Technical Information

P.O. Box 62

Oak Ridge, TN 37831 ;

(615) $576-8401$.

This report is publicly available from the:

National Technical information Service

Department of Commerce

5285 Port Royal Road

Springfield, Virginia 22161

(703) $487-4650$ 


\section{DISCLAIMER}

\section{Portions of this document may be illegible in electronic image products. Images are produced from the best available original document.}




\title{
Nonlinear Hybrid Simulation of Toroidicity-induced Alfvén Eigenmode
}

\author{
G. Y. Fu and W. Park \\ Princeton Plasma Physics Laboratory, Princeton University \\ P. O. Box 451 \\ Princeton, New Jersey 08543, U.S.A.
}

(August 18, 1994)

\begin{abstract}
Gyrokinetic/Magnetohydrodynamics hybrid simulations have been carried out using MH3D-K code to study the nonlinear saturation of the toroidicityinduced Alfvén eigenmode driven by energetic particles in a tokamak plasma. It is shown that the wave particle trapping is the nonlinear saturation mechanism for the parameters considered. The corresponding density profile flattening of hot particles is observed. The saturation amplitude is proportional to the square of linear growth rate. In addition to TAE modes, a new $n=1$, $m=0$ global Alfvén eigenmode is shown to be excited by the energetic particles.
\end{abstract}

52.35.Bj, 52.65.+z, 52.55.Pi

Typeset using REVTEX 
The toroidicity-induced Alfvén eigenmode (TAE) has received a great deal of attention recently in fusion research community. Experiments have shown that TAE mode can be strongly destabilized by energetic ions introduced by neutral beam injection heating or ion cyclotron radio frequency wave heating in tokamak plasmas. The instability is driven by the free energy associated with the fast particle density gradient through wave particle resonant interaction. The unstable TAE mode may in turn lead to large losses of energetic particles. This will have important implications for the design of tokamak reactor where the fusion product alpha particles have velocities comparable to Alfvén phase velocity and have a peaked density profile near the center of plasma. The lost alpha particles induced by the TAE instability can seriously damage the tokamak first wall. At present, D-T experiments in Tokamak Fusion Test Reactor [1] (TFTR) are being carried out to study the influence of fusion alpha particles on the TAE modes. Thus, it is of interest to assess the nonlinear saturation of the TAE modes.

In this work, nonlinear gyrokinetic/Magnetohydrodynamics (MHD) hybrid simulations have been carried out using MH3D-K code [2] to study the TAE instability driven by energetic particles in a tokamak plasma. The aim of this study is to determine the nonlinear saturation mechanism and associated fast particle transport. In our model, the plasma is divided into two parts: the bulk part which contains thermal electrons and ions, and the energetic part of hot ions. The bulk part is described by the ideal MHD equations, whereas the hot ions are described by the gyrokinetic equations [3]. The effects of hot ions are coupled to bulk part motion through the pressure stress tensor term in the momentum equation as follows:

$$
\rho_{b} \frac{d \mathbf{v}_{b}}{d t}=-\nabla P_{b}-\nabla \cdot \mathbf{P}_{h}+\mathbf{J} \times \mathbf{B},
$$

where the subscript $b$ denotes the bulk part, the subscript $h$ denotes the hot ion component, $P_{b}$ is the isotropic pressure of the bulk plasma, and the $P_{h}$ is the pressure stress tensor of the hot ions and is given by 


$$
\mathbf{P}_{h}=P_{\perp} \mathbf{I}+\left(P_{\|}-P_{\perp}\right) \mathrm{bb}
$$

and

$$
\left(\begin{array}{c}
P_{\|} \\
P_{\perp}
\end{array}\right)=\int d^{3} v F_{h}\left(\begin{array}{c}
M u^{2} \\
\mu B
\end{array}\right)
$$

Here, $\mathrm{b}$ is the unit vector along the magnetic field line, $F_{h}=F_{h}(\mathbf{R}, u, \mu)$ is the distribution function of the hot ions with $\mathbf{R}$ being the position of guiding centers, $u$ the parallel velocity, and $\mu$ the magnetic moment. This distribution function is calculated by following a set of particles using the gyrokinetic equation with the self consistent electromagnetic field. Equation 1 is closed by the ideal MHD Ohm's law and the Maxwell equations. The system of equation is solved as an initial value problem. We note here that our model is fully self-consistent, including self-consistent effects of hot particles on the MHD dynamics and the nonlinear MHD mode coupling.

In the simulations, we used following parameters and profiles for the most cases: the aspect ratio $R / a=6$, the safety factor profile $q=1.2+0.9(r / a)^{2}$, the plasma density profile $\rho=\rho_{0}\left(1-0.8(r / a)^{2}\right)$, the bulk plasma beta $\beta_{b}(0)=0.2 \%$, and hot particle beta $\beta_{h}(0)$ on order of percent. The particle velocity distribution is a Maxwellian in parallel direction with the mean value equals to the Alfvén speed at the center of plasma. The perpendicular velocity is negligible. The number of particles used ranges from twenty thousands to two hundred thousands.

We first describe our simulation results in linear regime. Figure $1(\mathrm{a})$ shows the contour plot of the plasma velocity stream function $u$ for a converged linear $n=1$ TAE mode. The corresponding radial eigenmode structure is shown in Figure 1(b) for several poloidal modes. The real frequency (normalized to the Alfvén frequency $v_{A} / R$ ) is $\omega=0.37$. The hot particle induced linear growth rate $\gamma_{h}$ is $\gamma_{h} / \omega=0.14$. The results are obtained with central hot particle beta of $\beta_{h}(0)=3.3 \%$ and two hundred thousand particles. The calculated real frequency, mode structure and growth rate agree reasonawly well with the results of a linear 
kinetic MHD eigenvalue code NOVA-K $[4,5]$, although our numerical equilibrium with selfconsistent anisotropic effects is not identical to that used in NOVA-K code. Our hybrid code has also been benchmarked using the energy conservation. We have derived analytically an energy conservation law from our physical model. Our numerical simulations show that the total energy is indeed well conserved.

In addition to TAE modes, a new global Alfvén eigenmode (GAE) is found to be excited by hot particles in the linear regime. Figure 2 shows the frequency spectrum of the velocity stream function for the $m=0$ poloidal component. We see that, besides the usual TAE peak at $\omega_{T A E}=0.37$, there is another peak at $\omega=1.05$ which is about three times the TAE frequency. This high frequency mode is identified as the $n=1, m=0$ GAE mode with frequency close to the minimum of the $n=1, m=0$ shear Alfvén continuum at the plasma center. Our results also indicate that the GAE mode persists in the nonlinear regime. This new GAE mode may be related to the experimental results in TFTR [6], where a high frequency mode was observed with its frequency about three times the TAE frequency.

In the nonlinear regime, our results indicate that the wave particle trapping is the nonlinear saturation mechanism of TAE mode [7]. Figure 3 shows the nonlinear evolution of kinetic energy of the bulk part for a $n=1 \mathrm{TAE}$ mode for two cases: one with a single $n=1$ perturbation (dashed line), and the other with multiple $n$ perturbation including $n=0,1$ and 2 (solid line). We see that the saturation level with single $n$ case is approximately the same as the multiple $n$ case. Thus, our results indicate that the nonlinear mode coupling is not responsible for the TAE saturation, at least for the parameters studied here. Other possible saturation mechanisms includes stochastic particle loss and nonlinear wave particle trapping. First, large loss of resonant particle can be induced when the TAE amplitude exceeds a stochastic threshold such that the particle orbit become chaotic. When this happens, the hot particle drive is diminished and the mode saturates. This scenario is presumed to be applicable when the hot particle drive is sufficiently large [8]. Second, at smaller hot 
particle drive, the TAE mode can still saturate due to nonlinear wave particle trapping, as suggested in Ref. 9. In this scenario, the resonant particles can be trapped in the TAE wave. The corresponding nonlinear bounce frequency $\omega_{b}$ is proportional to the square root of the mode amplitude. As a consequence of nonlinear trapping, the hot particle density profile is flattened locally on time scale of $1 / \omega_{b}$ and the hot particle drive diminishes to zero. Correspondingly, the mode saturates at $\omega_{b} \sim \gamma_{h}$, where $\gamma_{h}$ is the linear growth rate induced by hot particles. This implies that the saturation amplitude scales as linear growth rate squared. Our numerical results support this wave particle trapping mechanism. Figure 4 shows the saturation level $\delta B_{r} / B$ as a function of the normalized linear growth rate $\gamma_{h} / \omega$, where $\delta B_{\tau}$ is the perturbed radial magnetic field for $\mathrm{m}=2$ poloidal mode. We see that our numerical results (solid dots) agree well with the expected scaling of $\delta B_{r} \propto \gamma_{h}^{2}$ which is indicated by the solid line. For our parameters, it can be estimated that $\omega_{b} / \omega \approx 3 \sqrt{\delta B_{r} / B}$. Thus, in term of $\omega_{b}$, the saturation level is given by $\omega_{b} \approx 0.7 \gamma_{h}$. Figure 5 shows the hot particle distribution functions versus poloidal flux $\Psi$ at $t=0$ (dashed line) and at $t=60 R / v_{A}$ (solid line). There is clearly a local flattening at about $\Psi=0.4$ surface where the wave particle resonance condition is satisfied. The results of Fig. 5 are obtained with a slice of total distribution for which particles have velocities close to the Alfvén speed in order to observe a clear local flattening. Similar result of local distribution flattening has also been obtained in Ref. 10 using a quasilinear kinetic dispersion relation.

In conclusion, we have demonstrated using a fully self-consistent simulation that the wave particle trapping is the dominating mechanism for the TAE saturation. In addition to TAE modes, a new $n=1, m=0$ global Alfvén eigenmode is shown to be excited by the energetic particles. Future work will assess possible importance of other TAE saturation mechanisms in broader range of parameter space.

This work is supported by the U.S. Department of Energy under Contract No. DEAC02-76-CHO-3073. 


\section{REFERENCES}

[1] R. J. Hawryluk et al., Phys. Rev. Lett. 72, 3530 (1994).

[2] W. Park et al., Phys. Fluids B4, 2033 (1992).

[3] W. W. Lee, J. Comput. Phys. 72, 243 (1987)

[4] C. Z. Cheng, Phys. Reports 211, 1 (1992).

[5] G. Y. Fu, C. Z. Cheng and K. L. Wong, Phys. Fluids B5, 4040 (1993).

[6] K. L. Wong et al., Phys. Fluids B4, 2122 (1992).

[7] G. Y. Fu and W. Park, Annual International Sherwood Theory meeting, 1994.

[8] Heidbrink et al., Phys. Fluids B5, 2176 (1993).

[9] H. L. Berk, B. N. Breizman, and H. Ye, Phys. Rev. Lett. 68,3563 (1992).

[10] Y. Wu and R. White, Phys. Plasmas 1, 2733 (1994). 


\section{FIGURES}

FIG. 1. (a) Contour plot of fluid velocity stream function $u$; (b) the fluid velocity stream function $u_{m}(r)$ versus the normalized radius $r / a$ for several poloidal modes.

FIG. 2. Frequency spectrum of the fluid velocity function $u_{0}(\omega)$ for the $n=1, m=0$ mode.

FIG. 3. Nonlinear evolution of $E_{k}$ for a single $n=1$ perturbation (dashed line) and for multiple $n$ perturbation (solid line).

FIG. 4. The saturation amplitude of the normalized perturbed radial magnetic field $\delta B_{\tau} / B$ as a function of the normalized linear growth rate $\gamma_{h} / \omega$.

FIG. 5. The particle distribution functions versus radial variable poloidal flux $\Psi$ at $t=0$ (dashed line) and at $t=60 R / v_{A}$ (solid line). 

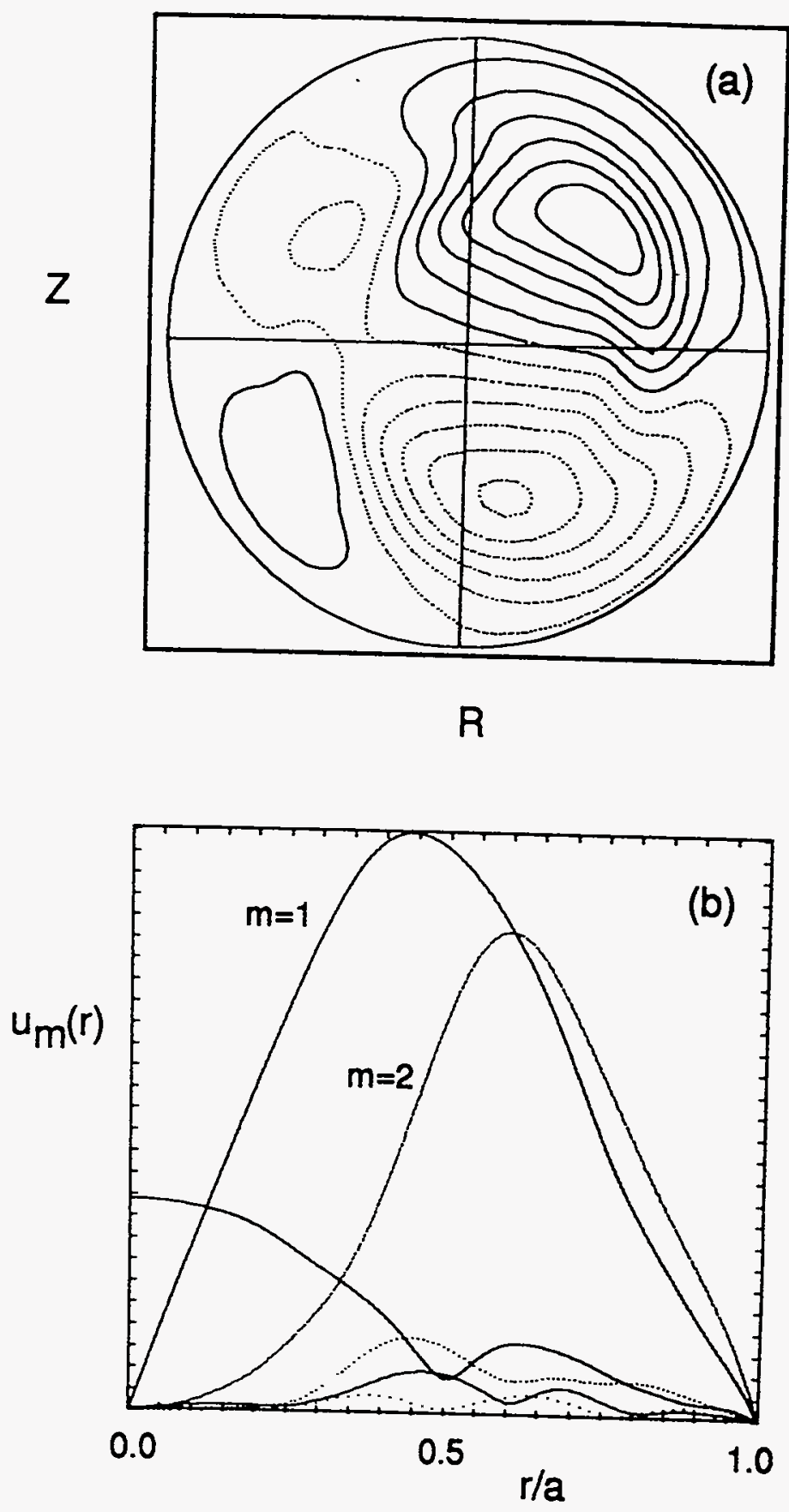

Fig. 1 


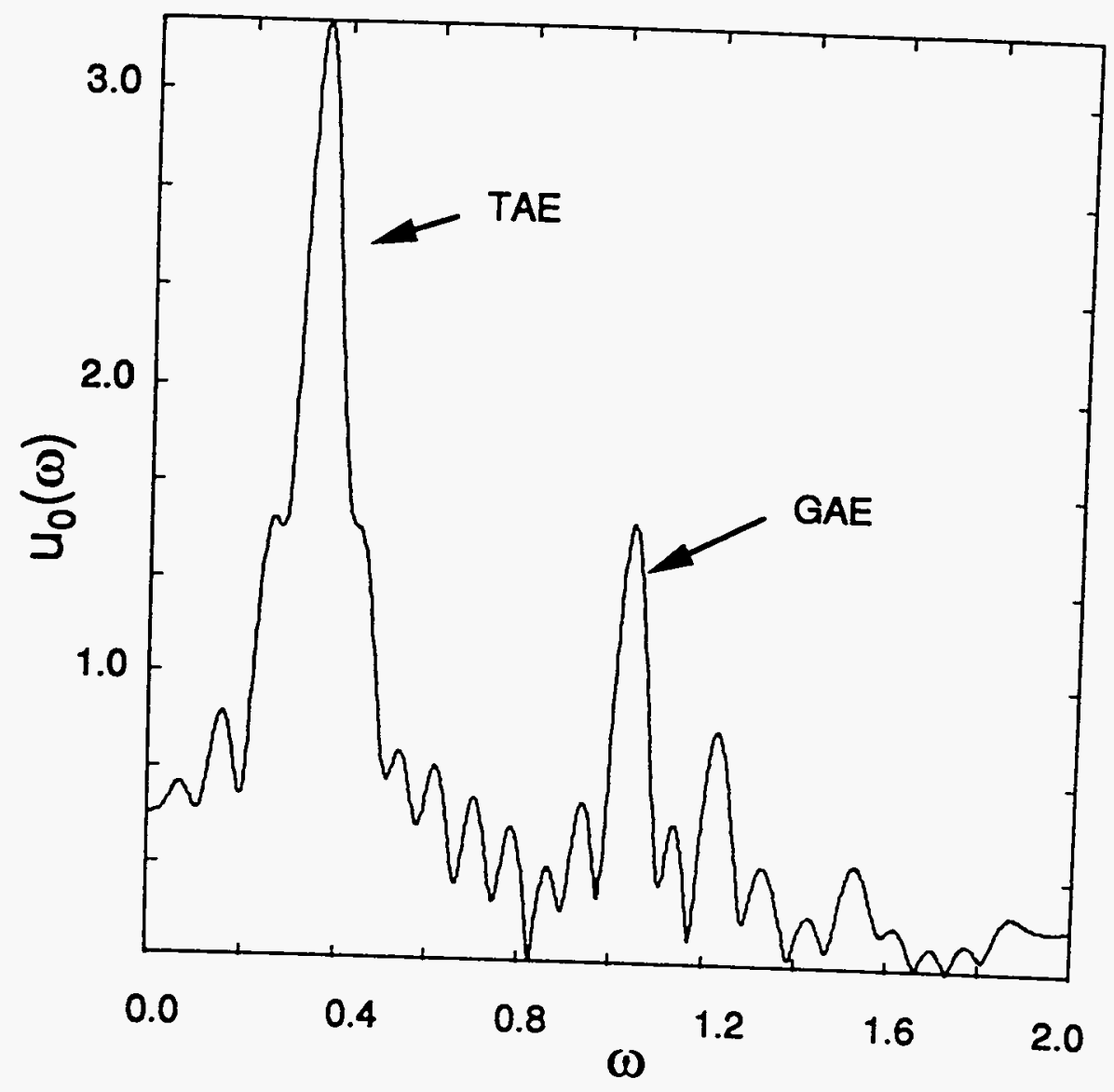

Fig. 2 


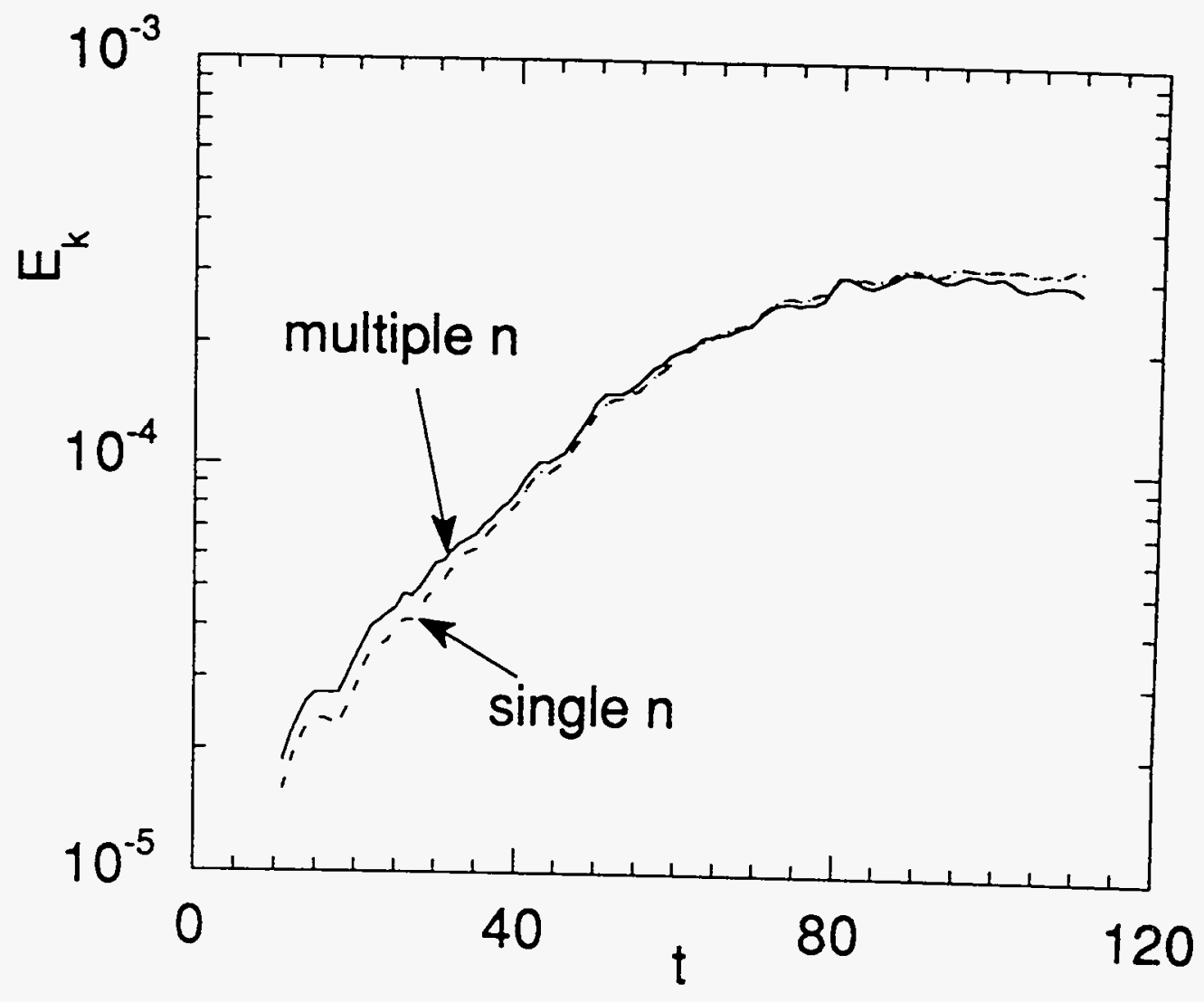

Fig. 3 


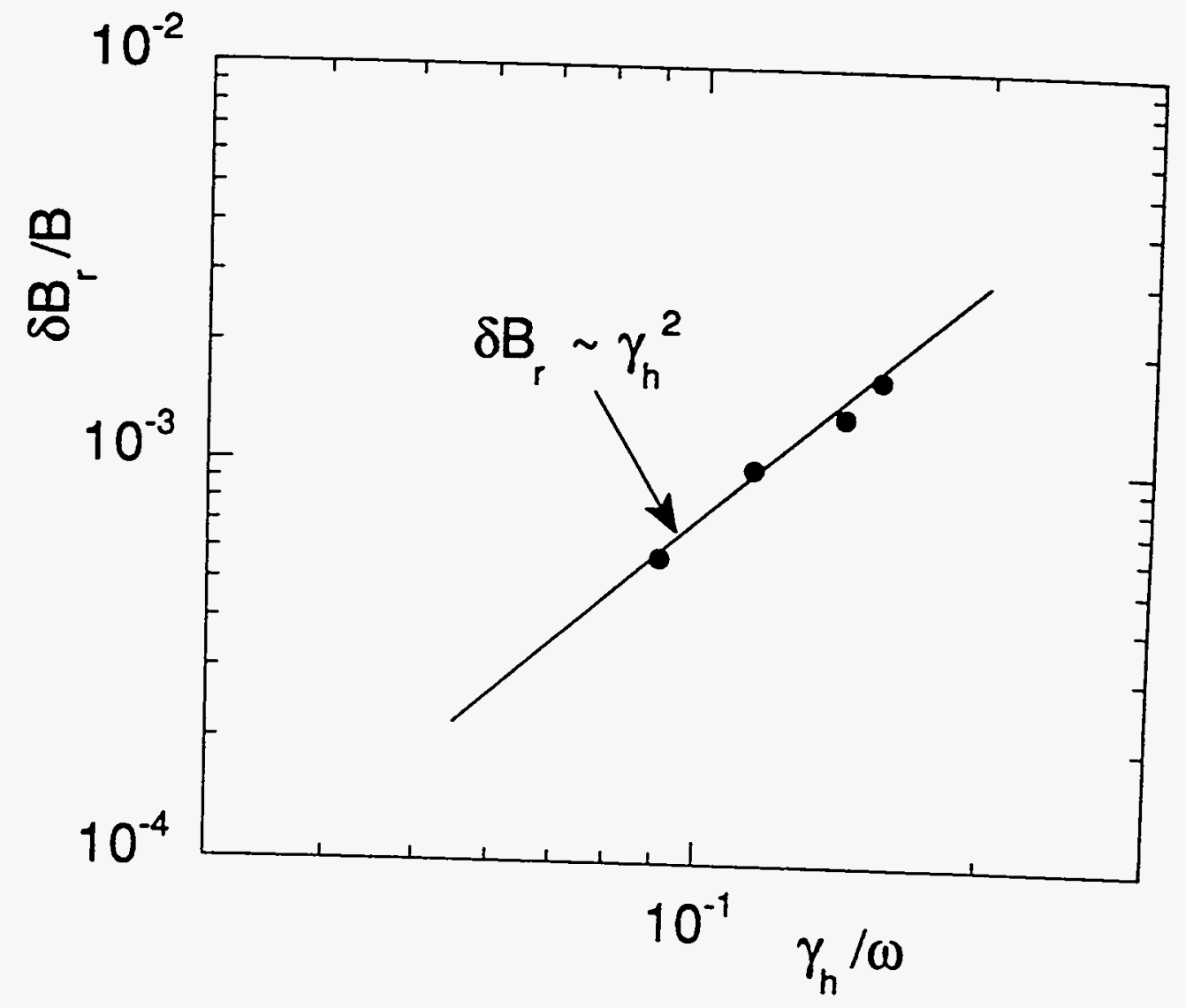

Fig. 4 


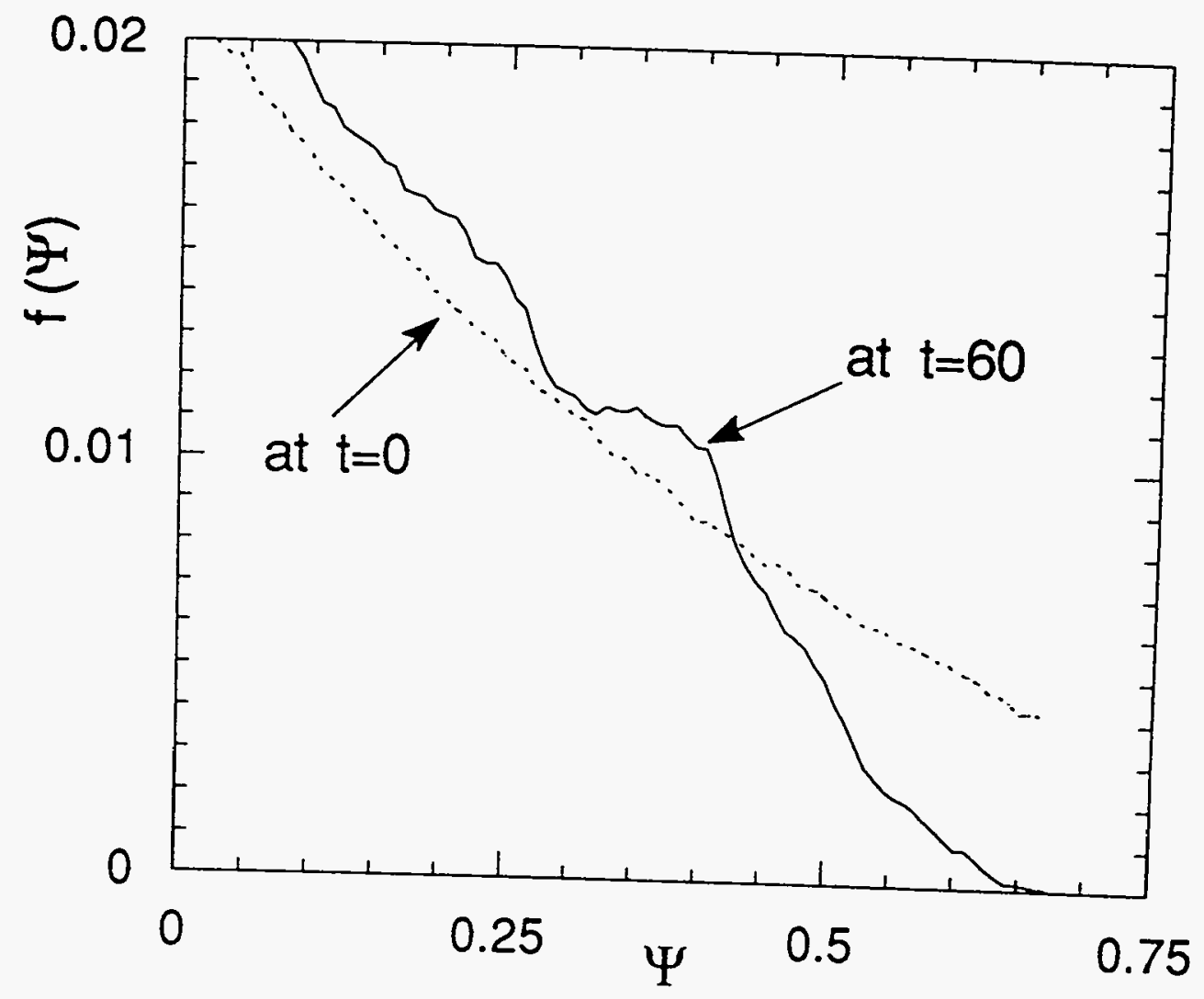

Fig. 5 
Dr. F. Paoloni, Univ. of Wollongong, AUSTRALIA

Prof. R.C. Cross, Univ. of Sydney, AUSTRALIA

Plasma Research Lab., Australian Nat. Univ., AUSTRALIA

Prof. I.R. Jones, Flinders Univ, AUSTRALIA

Prof. F. Cap, Inst. for Theoretical Physics, AUSTRIA

Prof. M. Heindler, Institut für Theoretische Physik, AUSTRIA

Prof. M. Goossens, Astronomisch instituut, BELGIUM

Ecole Royale Militaire, Lab. de Phy. Plasmas, BELGIUM

Commission-European, DG. XII-Fusion Prog., BELGIUM

Prof. R. Bouciqué, Rijksuniversiteit Gent, BELGIUM

Dr. P.H. Sakanaka, instituto Fisica, BRAZIL

Prof. Dr. I.C. Nascimento, Instituto Fisica, Sao Paulo, BRAZIL Instituto Nacional De Pesquisas Espaciais-INPE, BRAZIL Documents Office, Atomic Energy of Canada Ltd., CANADA

Ms. M. Morin, CCFMTtokamak de Varennes, CANADA

Dr. M.P. Bachynski, MPB Technologies, Inc., CANADA

Dr. H.M. Skarsgard, Univ. of Saskatchewan, CANADA

Prof. J. Teichmann, Univ. of Montreal, CANADA

Prof. S.R. Sreenivasan, Univ. of Calgary, CANADA

Prof. R. Marchand, INRS-Energie et Materiaux, CANADA

Dr. R. Bolton, Centre canadien de fusion magnétique, CANADA

Dr. C.R. James., Univ. of Alberta, CANADA

Dr. P. Lukác, Komenského Universzita, CZECHO-SLOVAKIA

The Librarian, Culham Laboratory, ENGLAND

Library, R61, Rutherford Appleton Laboratory, ENGLAND

Mrs. S.A. Hutchinson, JET Library, ENGLAND

Dr. S.C. Sharma, Univ. of South Pacific, FIJI ISLANDS

P. Măhönen, Univ. of Helsinki, FINLAND

Prof. M.N. Bussac, Ecole Polytechnique, FRANCE

C. Mouttet, Lab. de Physique des Milieux lonisés, FRANCE

J. Padet, CEN/CADARACHE - Bat 506, FRANCE

Prof. E. Economou, Univ. of Crete, GREECE

Ms. C. Rinni, Univ. of loannina, GREECE

Preprint Library, Hungarian Academy of Sci., HUNGARY

Dr. B. DasGupta, Saha Inst. of Nuclear Physics, INDIA

Dr. P. Kaw, Inst. for Plasma Research, INDIA

Dr. P. Rosenau, Israel Inst. of Technology, ISRAEL

Librarian, Intemational Center for Theo Physics, ITALY

Miss C. De Palo, Associazione EURATOM-ENEA , ITALY

Dr. G. Grosso, Istituto di Fisica del Plasma, ITALY

Prof. G. Rostangni, Istituto Gas lonizzati Del Cnr, ITALY
Dr. H. Yamato, Toshiba Res \& Devel Center, JAPAN

Prof. I. Kawakami, Hiroshima Univ., JAPAN

Prof. K. Nishikawa, Hiroshima Univ., JAPAN

Librarian, Naka Fusion Research Establishment, JAERI, JAPAN

Director, Japan Atomic Energy Research Inst., JAPAN

Prof. S. Itoh, Kyushu Univ., JAPAN

Research Info. Ctr., National Instit. for Fusion Science, JAPAN

Prof. S. Tanaka, Kyoto Univ., JAPAN

Library. Kyoto Univ., JAPAN

Prof. N. Inoue, Univ. of Tokyo, JAPAN

Secretary, Plasma Section, Electrotechnical Lab., JAPAN

Dr. O. Mitarai, Kumamoto Inst. of Technology. JAPAN

Dr. G.S. Lee, Korea Basic Sci. Ctr., KOREA

J. Hyeon-Sook, Korea Atomic Energy Research Inst., KOREA

D.I. Choi, The Korea Adv. Inst. of Sci. \& Tech., KOREA

Prof. B.S. Liley, Univ. of Waikato, NEW ZEALAND

Inst of Physics, Chinese Acad Sci PEOPLE'S REP. OF CHINA Library, Inst. of Plasma Physias, PEOPLE'S REP. OF CHINA

Tsinghua Univ. Library, PEOPLE'S REPUBLIC OF CHINA

Z. Li, S.W. Inst Physics, PEOPLE'S REPUBLIC OF CHINA

Prof. J.A.C. Cabral, Instituto Superior Tecnico, PORTUGAL

Prof. M.A. Hellberg, Univ. of Natal, S. AFRICA

Prof. D.E. Kim, Pohang Inst. of Sci. \& Tech., SO. KOREA

Prof. C.I.E.M.A.T, Fusion Division Library, SPAIN

Dr. L. Stenflo, Univ. of UMEA, SWEDEN

Library, Royal Inst. of Technology, SWEDEN

Prof. H. Wilhelmson, Chalmers Univ. of Tech., SWEDEN

Centre Phys. Des Plasmas, Ecole Polytech, SWITZERLAND

Bibliotheek, Inst. Voor Plasma-Fysica, THE NETHERLANDS

Asst. Prof. Dr. S. Cakir, Middle East Tech. Univ., TURKEY

Dr. V.A. Glukhikh,Sci. Res. Inst. Electrophys.I Apparatus, USSR

Dr. D.D. Ryutov, Siberian Branch of Academy of Sci., USSR

Dr. G.A. Eliseev, I.V. Kurchatov Inst., USSR

Librarian. The Ukr.SSR Academy of Sciences, USSR

Dr. L.M. Kovrizhnykh, Inst. of General Physics, USSR

Kemforschungsanlage GmbH, Zentralbibliothek, W. GERMANY

Bibliothek, Inst. Für Plasmaforschung, W. GERMANY

Prof. K. Schindler, Ruhr-Universitát Bochum, W. GERMANY

Dr. F. Wagner, (ASDEX), Max-Planck-Institut, W. GERMANY

Librarian, Max-Planck-Institut, W. GERMANY 